\title{
Welding Distortion Prediction for Multi-Seam Welded Pipe Structures using Equivalent Thermal Strain Method
}

\author{
Chunbiao $\mathrm{Wu}^{*}$, Chao Wang**, and Jae-Woong Kim***, \\ *Department of Mechanical Engineering, Graduate School of Yeungnam University, Gyeongsan, 38541, Korea \\ **School of Mechanical Engineering, Changshu Institute of Technology, Jiangsu, 215500, China \\ ***School of Mechanical Engineering, Yeungnam University, Gyeongsan, 38541, Korea
}

†Corresponding author: jaekim@ynu.ac.kr

(Received June 23, 2021; Revised August 12, 2021; Accepted August 27, 2021)

\begin{abstract}
Distortion prediction of a welded structure is an important way to improve work efficiency and ensure product quality during the fabrication process. Recently, the widely used approaches for evaluating residual deformation include the thermo-elastic-plastic finite element method (TEP-FEM) and the inherent strain method (ISM). The former can accurately simulate the entire welding process with excessive computational time, whereas the latter has great potential in the fast prediction of residual distortion in complex welded components. In this study, an equivalent thermal strain method based on inherent strain theory was proposed to predict residual deformation of the multi-seam welded pipe structures. Moreover, a full 3D TEP-FEM model was also developed to estimate the distributions of inherent strain in longitudinal (L-seam) and circumferential (C-seam) welds. To validate the accuracy of the proposed ISM, the welding distortion predicted by the proposed ISM is compared with the experimental data and TEP-FEM simulation results. It is discovered that the proposed ISM can be used to accurately predict welding-induced deformation in multi-seam welded pipe structures. Furthermore, compared with TEP-FEM simulation, the significant advantage of this approach is that the computing efficiency can be increased by about 50 times.
\end{abstract}

Key Words: Welding distortion prediction, Multi-seam welded pipe structure, Bending distortion, Thermo-elasticplastic FEM, Inherent strain method

\section{Introduction}

Cowl Cross Bar (CCB) system is one of the most critical automotive components, and its main function is to support man-machine interaction control equipment and enhance the strength of the car body. During its fabrication process, gas metal arc welding (GMAW), which is one high efficiency and steady joining process, is often used to connect the main pipes and the various types of functional brackets. However, welding-induced deformation always occurs inevitably due to uneven thermal expansion and shrinkage of welded metal in the welding process. It not only reduces the dimensional accuracy of the welded structure but also increases manufacturing cost due to additional post-weld correction treatment. Therefore, accurate and efficient pre- diction and control of welding deformation in the design stage is an important way to improve work efficiency and ensure product quality.

Up to now, the development of welding deformation prediction methods has mainly gone through the following important stages. In the first stage, experimental measurements and empirical formulas are usually used to determine the characteristics of welding distortion. Verhaeghe ${ }^{1)}$ conducted a comprehensive review on various approximate formulas to calculate the most typical welding distortion including longitudinal shrinkage, transverse shrinkage, and angular distortion. However, these empirical formulas only captured the distortion tendency of specific welding methods, materials, and welded structures. And they could not predict the value of welding deformation accurately and quantitatively. 
With the development of advanced computers and the improvement of numerical analysis theory, numerical simulation technologies based on the finite element method (FEM) were applied to predict the welding deformation in the second stage. In the 1970s, the thermo-elastic-plastic finite element method (TEP-FEM) was first proposed to simulate the welding process and calculate welding residual stresses and distortions by Ueda et al. ${ }^{2}$. Later, the effectiveness and accuracy of the TEP-FEM were also proved by other researchers ${ }^{3-6)}$. Venkatkumar et al. ${ }^{3)}$ presented the sequentially coupled thermo-mechanical FEM simulation to predict temperature distribution, residual stress, and distortion in a welded 304 stainless steel plate. Manurung et al. ${ }^{5)}$ developed a 3D TEP-FEM model to investigate the effect of welding sequence on the angular distortion during a multipass welding process. Meanwhile, a series of experiments were also conducted to validate the simulation results. Velaga et al. ${ }^{6}$ compared the weld characteristics between the longitudinal seam and circumferential butt weld joints of cylindrical components by using TEP-FEM simulation and experimental validation. Currently, the TEP-FEM is widely accepted to accurately model the welding process and capture temperature or stress-strain fields for various welded structures. However, for large-scale and complex structures, it isn't an applicable computational approach to predict welding deformation due to high nonlinearity and excessive computing time.

In the third stage, an elastic FEM analysis based on inherent strain theory ${ }^{7}$ was proposed to solve welding distortion problems with a short computational time. The inherent strain that exists in the welded joint is considered as the main source of generating welding residual stress and distortion ${ }^{8}$. If the inherent strain value is known, the welding-induced deformation can be estimated using the inherent strain method (ISM). However, there is no such operation to directly input inherent strain as an initial load in commercial FEM analysis software. Since then, researchers have made great efforts to solve this difficulty. Based on the different problem-solving ideas, the ISM can be divided into two types in the field of welding distortion prediction: (1) inherent deformation method; (2) equivalent thermal strain method.

The inherent deformation method has been frequently used to predict welding distortion of large-scale and complex welded structures. Four fundamental inherent deformation components are calculated by integrating the longitudinal inherent strain ( $\left.\varepsilon_{\text {longeitudinal }}^{\text {inhent }}\right)$ and transverse inherent strain $\left(\varepsilon_{\text {transversere }}^{\text {inhere }}\right)$ distributed on the crosssection through thickness direction according to the following equations ${ }^{9,10)}$.

$$
\begin{aligned}
& \delta_{\text {longitudinal }}^{*}=\frac{1}{h} \iint \varepsilon_{\text {longitudinal }}^{\text {inherent }} \mathrm{dydz} \\
& \delta_{\text {transverse }}^{*}=\frac{1}{h} \iint \varepsilon_{\text {transverse }}^{\text {inherent }} \mathrm{dydz} \\
& \theta_{\text {longitudinal }}^{*}=\frac{12}{h^{3}} \iint\left(z-\frac{h}{2}\right) \varepsilon_{\text {longitudinal }}^{\text {inherent }} \mathrm{dydz} \\
& \theta_{\text {transverse }}^{*}=\frac{12}{h^{3}} \iint\left(z-\frac{h}{2}\right) \varepsilon_{\text {transverse }}^{\text {inherent }} \mathrm{dydz}
\end{aligned}
$$

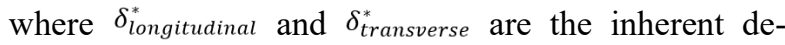
formation in the longitudinal and transverse directions, $\theta_{\text {longitudinal }}^{*}$ and $\theta_{\text {transverse }}^{*}$ are the nherent bending deformation in the longitudinal and transverse directions, respectively. $h$ is the thickness of the welded structures.

Then these obtained equivalent loads are assigned to the elastic FEM model to predict welding deformation of various types of welded joints. For example, Deng et al. ${ }^{11)}$ precisely predicted welding distortion for large welded structures using the inherent deformation method with experimental verification. Wang et al. ${ }^{12)}$ reported that an elastic FEM analysis based on inherent deformation theory and interface element is an effective and practical computational approach for welding distortion prediction in the fabrication of large-scale welded offshore structures. Moreover, Wang et al. ${ }^{13)}$ employed an inherent deformation method to evaluate welding distortion of the spherical welded structure produced by multi welding lines within a very short computing time.

On the other hand, the problem-solving idea of the equivalent thermal strain method is that the inherent strain is directly entered as the equivalent thermal strain to the FEM model. Because the equivalent thermal strain can also be transferred into the product of artificial thermal expansion coefficient ( $\left.\alpha^{\text {artificial }}\right)$ and artificial temperature gradient $(\Delta T)$, as shown in Eq. (5).

$$
\varepsilon^{\text {inherent }}=\varepsilon^{\text {equivalent }}=\alpha^{\text {artificial }} \cdot \Delta T
$$

where $\varepsilon^{\text {inherent }}$ and $\varepsilon^{\text {equivalent }}$ are defined as inherent strain and equivalent thermal strain, respectively.

Based on the above principle, Ha et al. ${ }^{14)}$ proposed a new kind of thermal distortion analysis method (SDB method) to predict welding distortion. In their study, a shell element model is assigned with a constant artificial thermal expansion coefficient and linear temperature gradient to simulate the shrinkage behavior near the weld. Later, the feasibility and accuracy of the SDB method were also verified in research results presented by Lee et al. ${ }^{15)}$. Moreover, Kim et al. ${ }^{16)}$ proposed a simplified thermal strain-based method with composite shell elements to investigate welding deformation of T-joint fillet welds. In their work, experiments and 3D 
TEP-FEM analysis were also conducted to verify the accuracy of the proposed ISM method.

From the above, the ISM analysis has been proved that has the ability to accurately predict welding distortion in various types of welded joints and large-scale welded structures within a short computing time. However, in the last two decades, a large number of published papers focused mainly on the improvement and application of the inherent deformation method. Related reports on using equivalent thermal strain methods to solve the problems of welding deformation are rare.

Thus, in this study, an equivalent thermal strain method was developed to predict the welding distortion induced by multi-seam welding in a welded pipe structure.
The general computation procedure of the proposed welding deformation prediction method is illustrated in Fig. 1. Firstly, a full 3D TEP-FEM numerical simulation was conducted to extract the value of inherent strain that occurred in a welded joint quantitatively. Secondly, according to the concept of Eq.(5), the inherent strain is directly assigned to an elastic FEM model for predicting the welding-induced distortion. Moreover, a series of welding experiments were also performed to confirm theaccuracy of simulation models.

\section{Welding experiment}

Fig. 2 shows a typical CCB automotive component design, where various brackets are joined to the left

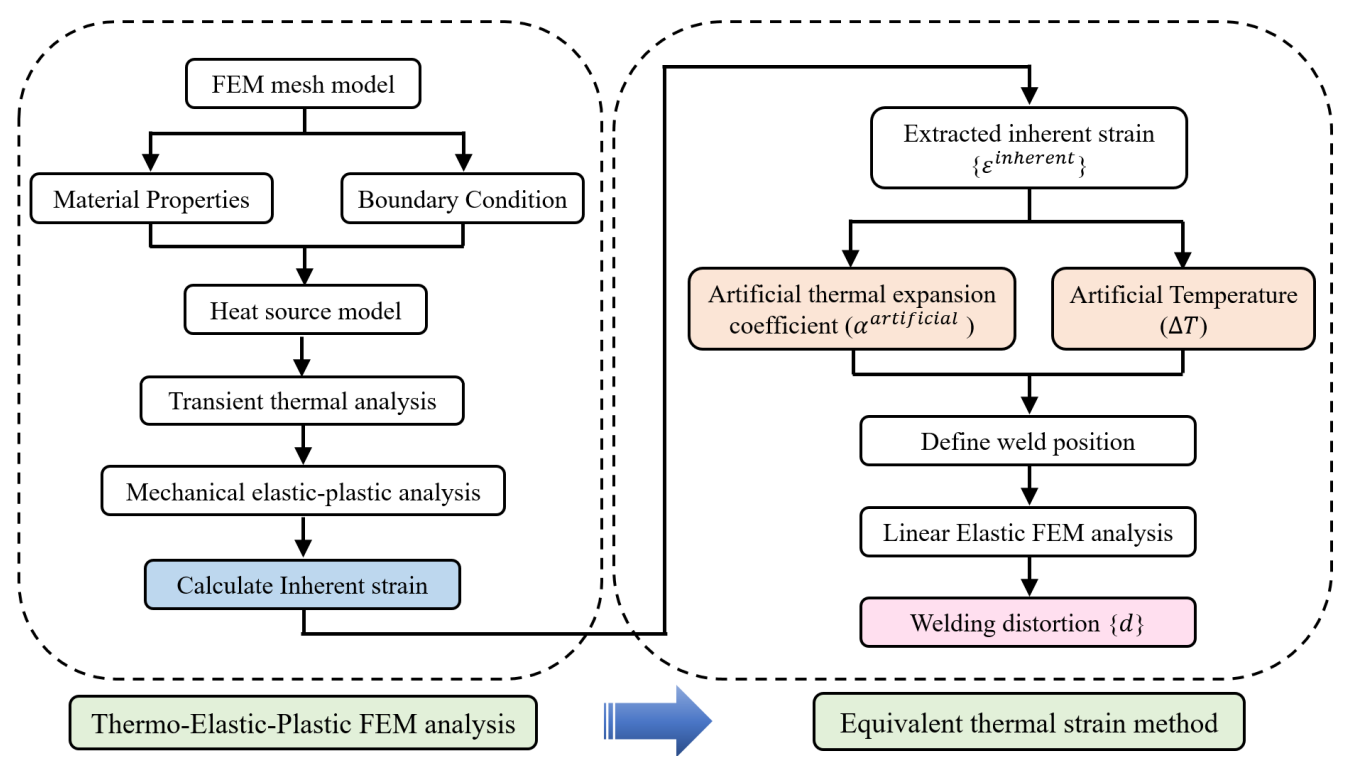

Fig. 1 Computation procedure of the proposed welding deformation prediction method

(b) URP functional bracket

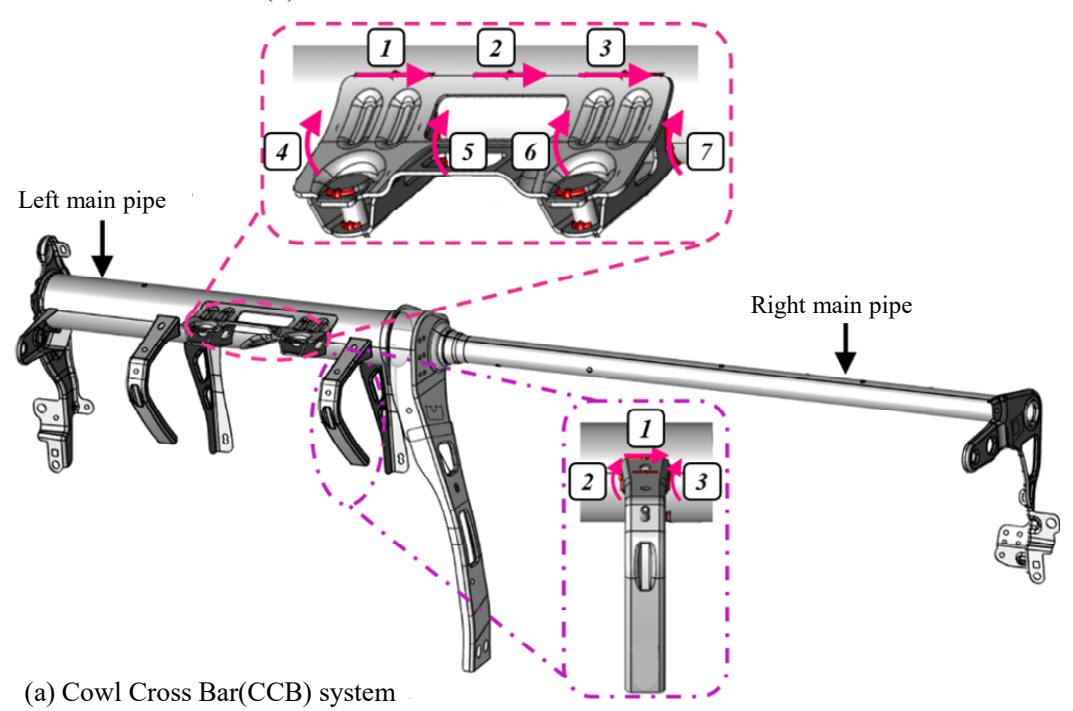

(c) KENN functional bracket

Fig. 2 Cowl Cross Bar (CCB) system and its welding details during assembly 
main pipe using the multi-seam GMAW process. And the welds comprise two basic patterns: longitudinal seam (L-seam) and circumferential seam (C-seam). During the assembly process, large welding deformation often occurs in the main pipe structure. Thus, to simplify the welding experiments, brackets are ignored and only the pipe component is heated by a welding arc with the filler metal.

To confirm the validity and accuracy of the following simulation models, a series of experiments were carried out and the predicted welding distortions are compared with the measured results. In this experiment, a numerical control automatic welding system to was designed perform L-seam and C-seam welding of a pipe, as shown in Fig. 3. The outer diameter, length, and thickness of the welded specimen are $850 \mathrm{~mm}, 54 \mathrm{~mm}$, and $2 \mathrm{~mm}$, respectively. The material is low carbon steel STKM 13B. And the welding parameters of the L-seam and $\mathrm{C}$-seam used in our experiments are identical and are presented in Table 1. The specific details of the welding experiment can be found in the previous study presented by $\mathrm{Wu}$ et al. ${ }^{17)}$. A series of GMAW experimental specimens with different weld seams are illustrated in Fig. 4.

During L-seam and C-seam welding process, local expansion and shrinkage of welded pipe in the axial, circumferential, and thickness direction could occur. Among them, due to a large gradient of axial shrinkage in heating and non-heating zones, a serious bending distortion will be produced in a long pipe, as shown in Fig. 5. Other deformations are relatively small can be ignored, so only welding-induced bending distortion

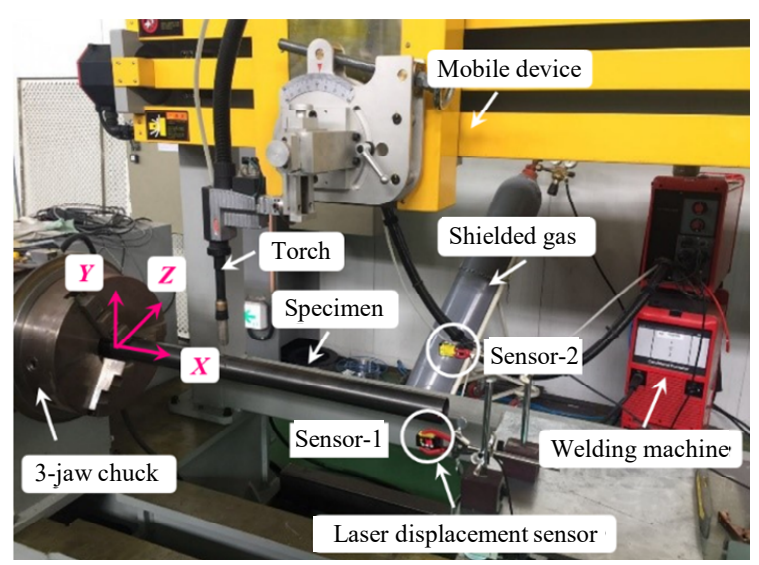

Fig. 3 Numerical control automatic welding system

Table 1 Welding condition

\begin{tabular}{|c|c|c|c|c|}
\hline Parameter & $\begin{array}{c}\text { Welding } \\
\text { voltage }\end{array}$ & $\begin{array}{c}\text { Welding } \\
\text { current }\end{array}$ & $\begin{array}{c}\text { Welding } \\
\text { speed }\end{array}$ & Efficiency \\
\hline Value & $16.2 \mathrm{~V}$ & $131 \mathrm{~A}$ & $0.5 \mathrm{~m} / \mathrm{min}$ & 0.65 \\
\hline
\end{tabular}

was investigated in this study.

To measure the welding-induced bending distortion, laser displacement sensors are utilized to record the history of the free end displacement in a welded pipe, as shown in Fig. 3. Two sensors are set in orthogonal directions to measure the displacements in Y-axis and Z-axis coordinates, respectively. Meanwhile, the random errors of experiments can be minimized by calculating the mean of multiple measured values.

\section{Estimation of inherent strain}

\subsection{Definition of inherent strain}

Based on the inherent strain theory first proposed by
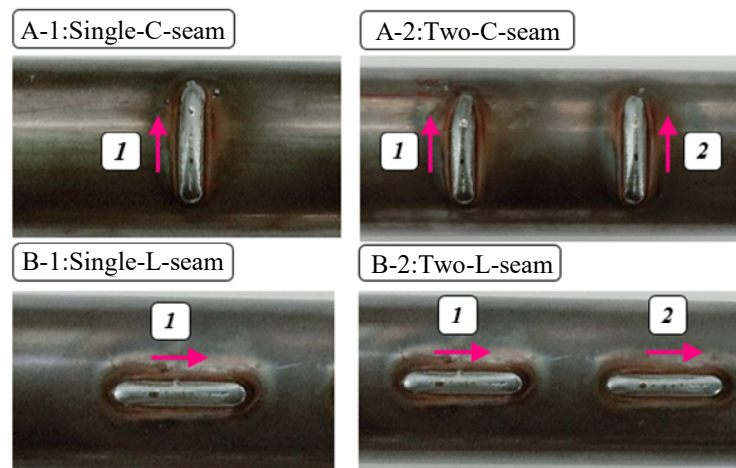

B-2:Two-L-seam
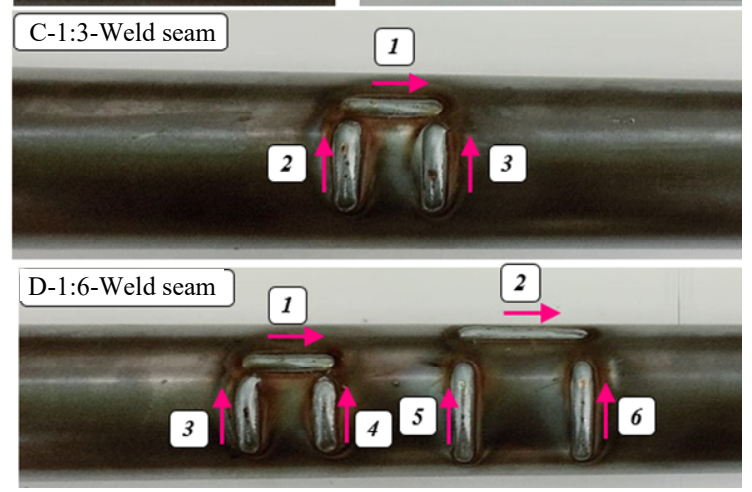

Fig. 4 A series of GMAW experimental specimens

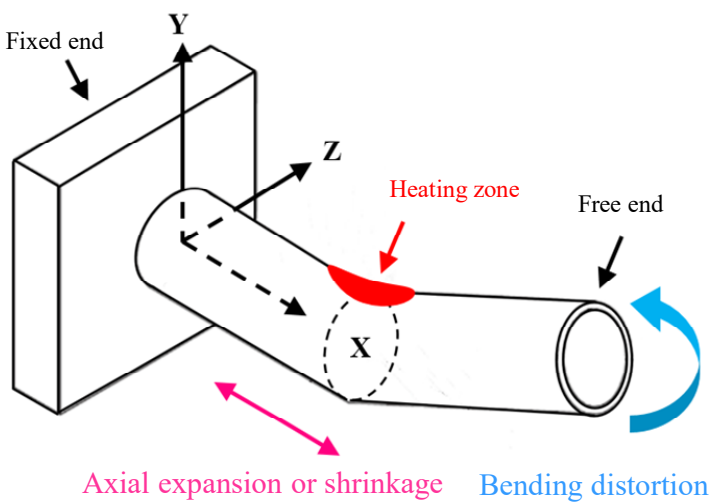

Fig. 5 Welding-induced bending distortion in a long pipe 
Ueda et al. ${ }^{18)}$, the welding-induced residual stresses and distortions are considered to be produced by the inherent strain $^{19)}$. In structural analysis, the total strain $\varepsilon^{\text {total }}$ produced by the welding process can be divided into multiple strain components, as shown in Eq.(6)

$$
\varepsilon^{\text {total }}=\varepsilon^{T}+\varepsilon^{E}+\varepsilon^{P}+\varepsilon^{P h}+\varepsilon^{C}
$$

where $\varepsilon^{T}, \varepsilon^{E}, \varepsilon^{P}, \varepsilon^{P h}$, and $\varepsilon^{C}$ in this equation denote the thermal strain, elastic strain, plastic strain, phase transformation strain, and creep strain, respectively.

Furthermore, the total strain can be also defined as a summation of the elastic strain and inherent strains ( $\left.\varepsilon^{\text {inherent }}\right)$, given by Eq.(7)

$$
\varepsilon^{\text {total }}=\varepsilon^{E}+\varepsilon^{\text {inherent }}
$$

From the above-mentioned Eqs. (6) and (7), the inherent strain can be expressed as a summation of all inelastic strain components.

$$
\varepsilon^{\text {inherent }}=\varepsilon^{T}+\varepsilon^{P}+\varepsilon^{P h}+\varepsilon^{C}
$$

It is noted that the thermal strain disappears when the temperature comes back to ambient temperature. Cho et al. $^{20)}$ concluded that phase transformation has less effect on the residual stress and distortion in low carbon steel. Thus, the strain produced by phase transformation can be ignored. Moreover, the creep strain is also neglected because the high-temperature period of the welding process is extremely short ${ }^{21)}$. Therefore, in this present study, the inherent strain is determined by the residual plastic strains generated throughout the pipe welding process.

$$
\varepsilon^{\text {inherent }}=\varepsilon^{P}
$$

\subsection{Thermal elastic-plastic FEM simulation}

Based on the inherent strain theory, if the inherent strain of the typical welded joints (L-seam and C-seam) is determined, the residual distortion produced by multi-seam welding can be predicted by using an elastic FEM analysis by assigning the value of inherent strain to the vicinity of the welded seams. Currently, the most frequently used approaches to estimate the inherent strain include experimental measurement and TEP-FEM numerical analysis. In this study, a three-dimensional TEPFEM model was developed to calculate the distribution of inherent strain in a single L-seam and C-seam welded pipe quantitatively.

The welding numerical simulation is considered to be a typical thermal-mechanical sequentially coupled issue.
During thermal analysis, a moving double ellipsoidal heat source model presented by Goldak et al. ${ }^{22)}$ is employed to simulate the heat flux generated by the welding arc with consideration of the effect of convection and radiation. Then, a transient heat transfer analysis is performed to capture temperature field distribution throughout the pipi welding process. Subsequently, the elastic-plastic mechanical analysis with large deformation theory is carried out using obtained temperature history as an input load for the calculation of stressstrain field and corresponding welding distortion. The details of the 3D TEP-FEM numerical simulation procedure of L-seam, C-seam, and multi-seam pipe welding were also described in the previous research ${ }^{17)}$. Finally, the distribution of inherent strain for typical welded joints was obtained by using the established TEP-FEM models.

In this study, the developed TEP-FEM models were also used to predict welding deformation of the multi-seam welded specimens. The same welding condition is utilized in both our experiments and simulations. When the deposition of each weld is done, a 5-second cooling process is introduced into the TEP-FEM model to simulate the process of torch moving and workpiece rotating for the next welding preparation. During the post-processing of simulation, welding-induced bending distortion predicted by TEP-FEM numerical analysis is extracted and compared with the measurement data, as shown in Fig. 6.

In the experiment procedure, it should be noted that the displacement recorded during the heating cycle has no definite physical significance. Because the workpiece is rotated to adjust the welding position, the measured points are continuously changing. Thus, only experimental results measured during the cooling process are illustrated in Fig. 6. Form this figure, it can be observed that the FEM simulation results match the experimental measurement well.

\subsection{Distribution of inherent strain}

In this study, the distribution of inherent strain in axial and circumferential directions dominates the formation of bending deformation in a welded pipe. On the other hand, the inherent strain in thickness direction has an insignificant effect on the current welding distortion. Thus, the value of this inherent strain component is assumed to be zero. Meanwhile, for the GMAW process, it is assumed that the welding bead is considered not to affect weld distortion in the ISM analysis ${ }^{16)}$.

Based on the developed TEP-FEM analysis computed results, the distributions of inherent strain (residual 


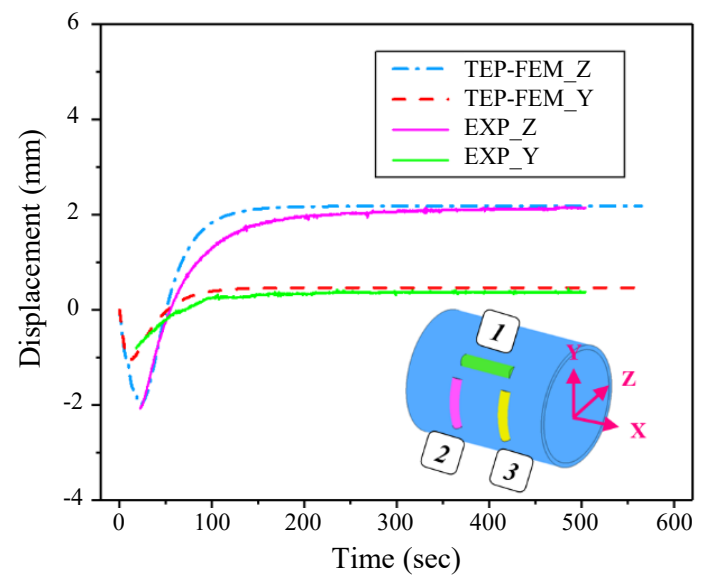

(a) 3-Weld seam

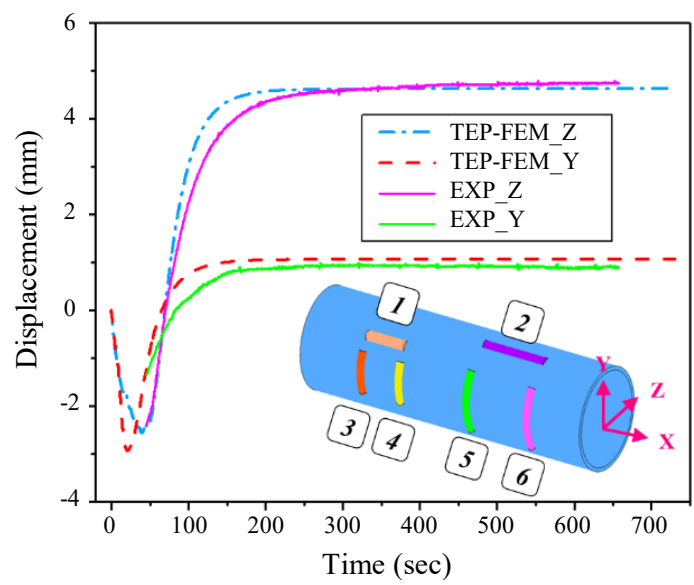

(b) 6-Weld seam

Fig. 6 Displacement histories in $\mathrm{Y}$ and $\mathrm{Z}$ coordinates during typical brackets welding.

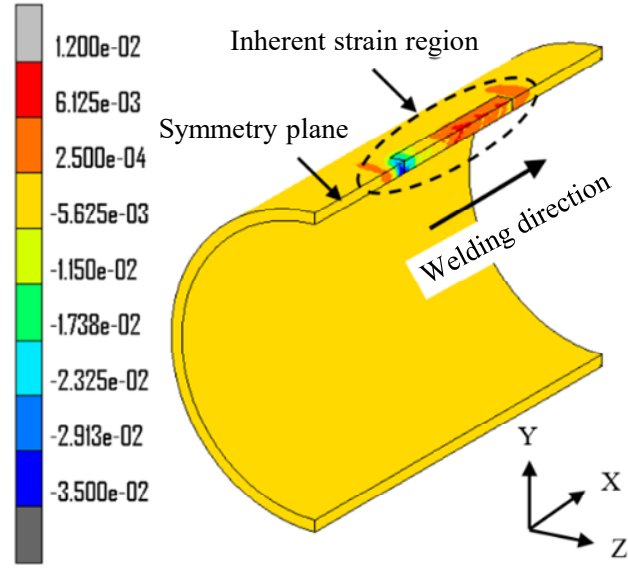

(a) Axial inherent strain

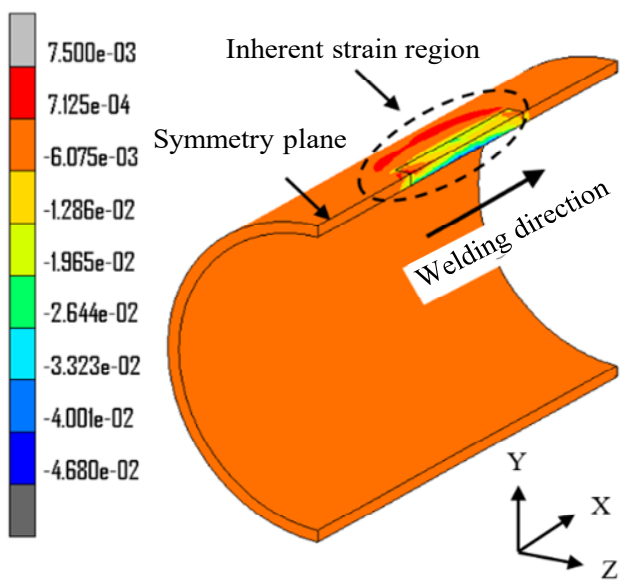

(b) Circumferential inherent strain

Fig. 7 Distribution of inherent strain in the axial and circumferential direction of L-seam welded pipes

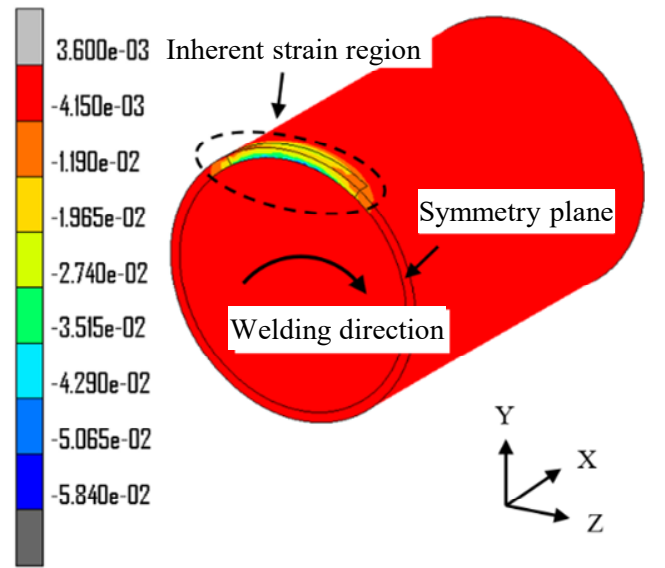

(a) Axial inherent strain

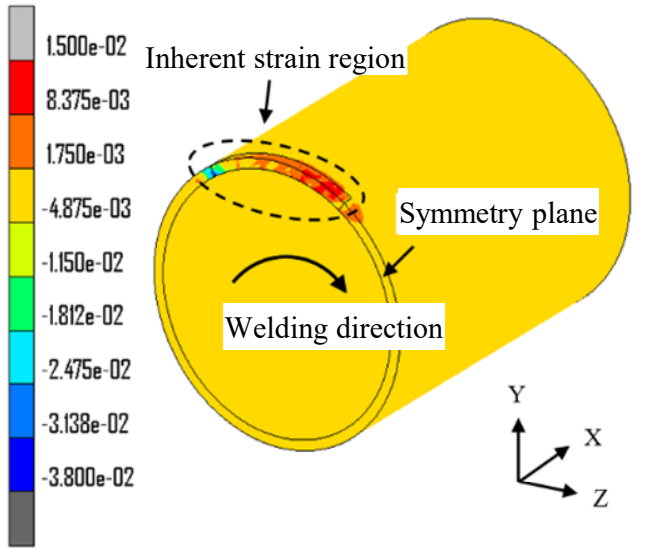

(b) Circumferential inherent strain

Fig. 8 Distribution of inherent strain in the axial and circumferential direction of C-seam welded pipes

plastic strain) in the axial and circumferential directions of L-seam and C-seam welded joints are illustrated in Fig. 7 and Fig. 8, respectively. Form these figures, it is discovered that the lager compressive inherent strain along the welding line occurs near the weld start position. This is considered due to that the generated constraint 
force provided by the surrounding material at the weld start position is bi-axial distribution, whereas the steady zone is on the uni-axial. In addition, the distribution of the inherent strain normal to the welding line maintains almost uniform along the welding direction.

To further investigate the characteristic of inherent strain, Fig. 9 compares the computed results of the distribution of axial and circumferential components on the middle cross-section normal to welding direction of L-seam and C-seam welded pipes. From Fig. 9, it is observed that the inherent strain is concentrated nearby the weld area and the maximum effective width of its region is approximately $10 \mathrm{~mm}$. Away from the welding line, the value of inherent strain is almost zero. Luo et al. ${ }^{8)}$ reported that the inherent strain produced by a specific welded structure is determined by the maximum temperature and constrain condition during the welding procedure. In this study, the same peak temperature can be observed during L-seam and C-seam welding processes. Thus, different magnitude and distribution of inherent strain are mainly caused by the difference of self-constraint characteristics in L-seam and C-seam welded joints

Within the region of inherent strain, the average values of axial and circumferential components throughout the thickness direction are evaluated on each cross-section perpendicular to the welding line, and the computed distributions along the welding direction for L-seam and C-seam welds are shown in Fig. 10. During the ISM analysis process, to avoid difficulty when assigning the computed distribution of inherent strains to the elastic FEM model, it is assumed that all components of inherent strain are considered to be of constant magnitude along the welding direction. As a good approximation, the constant inherent strain vector, i.e., $(-0.005,-0.010,0)$ for L-seam weld and $(-0.014,-0.001$,

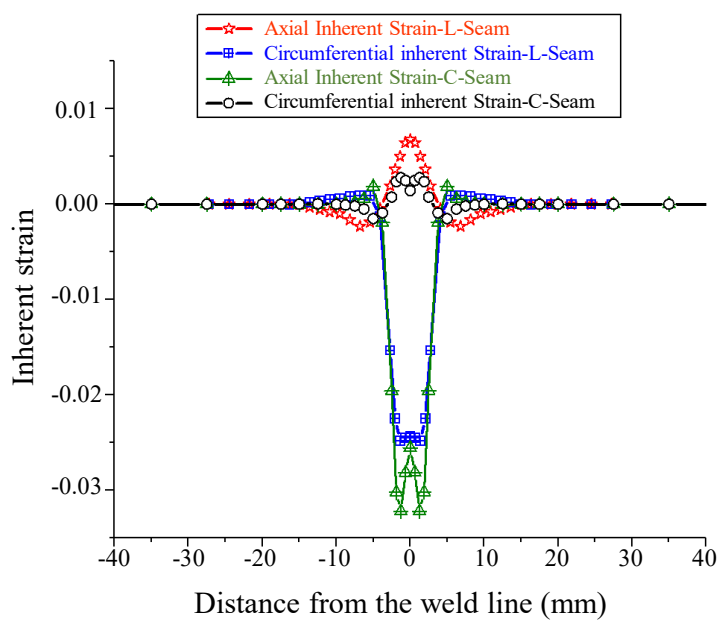

Fig. 9 Distribution of inherent strain on the middle crosssection at the neutral plane

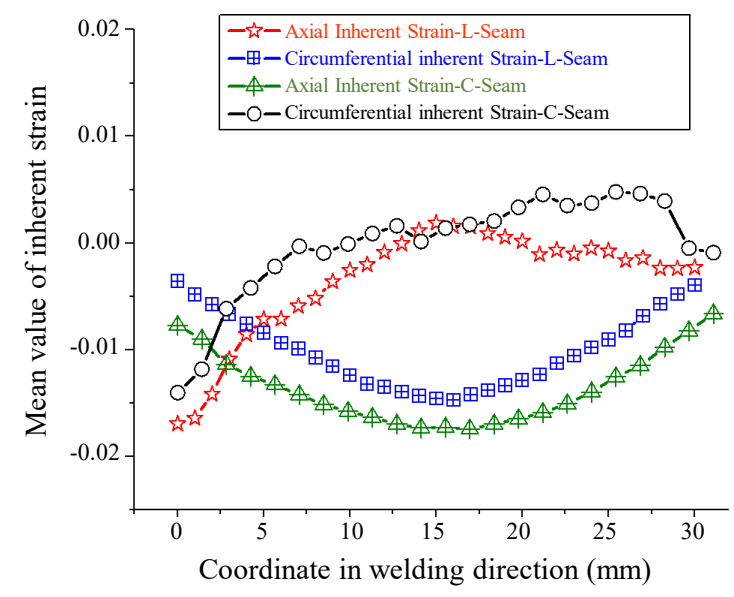

Fig. 10 Distribution of average of inherent strain alone the welding direction

0) for C-seam weld will be utilized in the elastic FEM model to predict welding distortion of multi-seam welded pipes.

\section{Elastic FEM analysis}

After the inherent strain of L-seam and C-seam welded joints has been obtained by using the developed TEP-FEM analysis, the residual distortion produced by welding can be computed by a linear elastic FEM analysis using the known inherent strain as an input load. To develop a method to apply the strain as an external load to the FEM model, the obtained inherent strain was transformed into an equivalent thermal strain, i.e., an orthotropic thermal expansion coefficient and temperature gradient, as shown in Eq.(10).

$$
\varepsilon_{i}^{\text {inherent }}=\alpha_{i}^{\text {artificial }} \cdot \Delta T ; i=x, y, z
$$

where $\alpha_{i}^{\text {artificial }}$ represents the artificial coefficient of thermal expansion in the $i^{\text {th }}$ direction in the coordinate system considering the features of the anisotropic distribution of inherent strain.

In the elastic FEM model, a 3D-solid element was adopted. The artificial temperature of the nodes within the region of inherent strain is taken as $1^{\circ} \mathrm{C}$, while all other nodes are set to zero. Furthermore, an orthotropic artificial thermal expansion coefficient with a constant negative value was assigned to all the elements of the inherent strain zone for effectively simulating the shrinkage behavior during the cooling process of welding. as shown in Fig. 11. The unit thermal load of each weld was activated step by step and a static equilibrium analysis was performed to calculate residual deformation induced by multi-seam welding. Because the proposed ISM method is an elastic static analysis proc- 


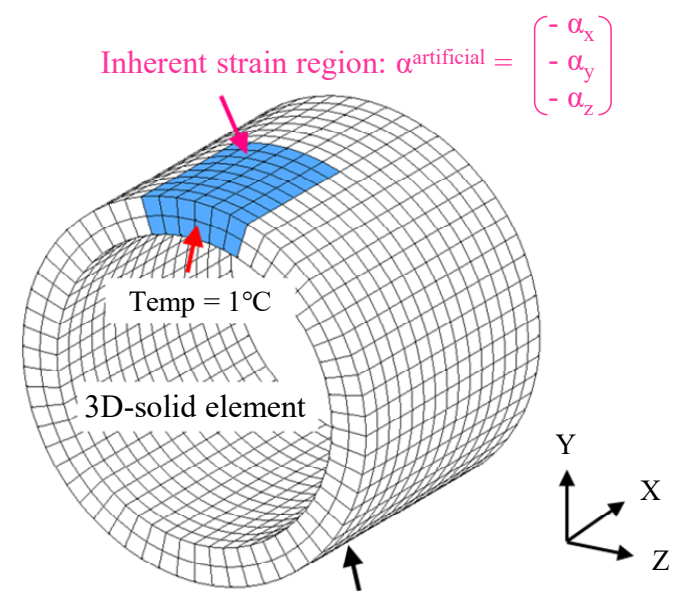

Non-Inherent strain region: $\alpha=0$; Temp $=0{ }^{\circ} \mathrm{C}$

Fig. 11 Schematics of mechanism of equivalent thermal strain method

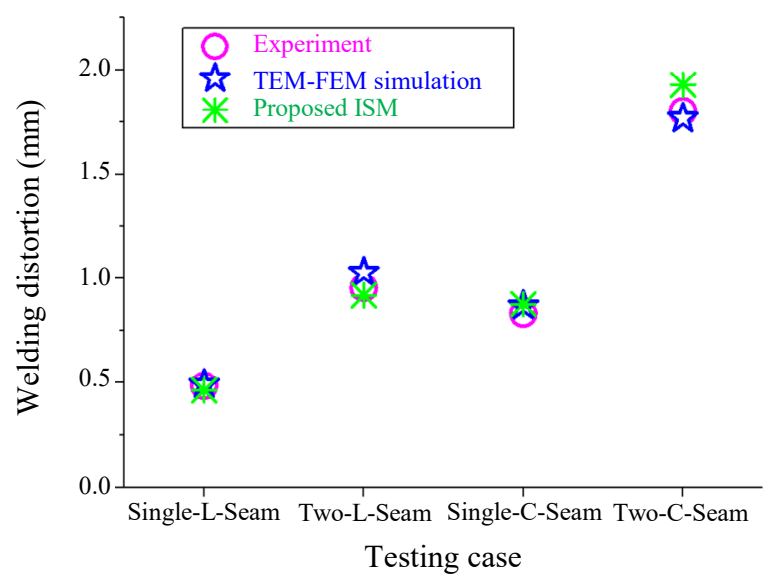

Fig. 12 Comparison of maximum bending distortion in simple welded joints among experiment, TEPFEM simulation, and proposed ISM

ess, it can save most of the computational time compared with the TEP-FEM simulation.

In this present study, two testing cases, i.e., simple welded joints and multi-seam welded structures, are performed to demonstrate the accuracy of the proposed equivalent thermal strain method. For the simple welded joints, the maximum bending distortion resulting from a single seam and two seams welding obtained by experiment, TEP-FEM simulation, and the proposed ISM are compared in Fig. 12. The results from Fig. 12
Table 3 Comparison of computational time between TEPFEM simulation and proposed ISM

\begin{tabular}{|c|c|c|}
\hline \multirow{2}{*}{ Case } & \multicolumn{2}{|c|}{ Computational time (min) } \\
\cline { 2 - 3 } & TEP-FEM simulation & Proposed ISM \\
\hline 3-Weld-Seams & 223 & 3.8 \\
\hline 6-Weld-Seams & 466 & 8.8 \\
\hline
\end{tabular}

discovered that the discrepancy between measurement data and numerical simulation results is acceptable. Thus, the proposed ISM can be used to accurately predict welding distortion. However, it should be noted that the time-saving advantages of the proposed ISM aren't particularly prominent in simple welded joints.

To further demonstrate the accuracy of the proposed ISM, it was also used to investigate the welding distortion of multi-seam welded structures. Table 2 shows the comparison of the maximum bending distortion among experiment, TEP-FEM, and proposed ISM in the multi-seam welded specimens. Very good consistency is observed in Table 2, and the efficiency and accuracy of this proposed ISM are validated again.

For complex and large-scale multi-seam welding, the computational time of the TEP-FEM simulation and proposed ISM is also compared in Table 3. Generally, compared with TEP-FEM simulation, the computing efficiency of the proposed ISM can be increased by about 50 times. That is because that the complex nonlinear elastic-plastic behavior of the welding process isn't taken into consideration. Especially for more welds, the advantage of computational efficiency is more significant.

\section{Conclusion}

In this study, a linear elastic FEM model based on the equivalent thermal strain method was developed for fast prediction of welding distortion in a multi-seam welded pipe. To estimate the distribution of inherent strain in typical L-seam and C-seam welded joints, a TEP-FEM numerical simulation was performed. Subsequently, the obtained inherent strain is assigned to the elastic FEM model for computing welding distortion. Moreover, a series of experiments were also conducted

Table 2 Maximum bending distortion of multi-seam welded structures

\begin{tabular}{|c|c|c|c|c|c|c|}
\hline \multirow{2}{*}{ Case } & \multicolumn{2}{|c|}{ Experimental data } & \multicolumn{2}{c|}{ TEP-FEM simulation } & \multicolumn{2}{c|}{ Proposed ISM } \\
\cline { 2 - 7 } & $d_{y}(\mathrm{~mm})$ & $d_{z}(\mathrm{~mm})$ & $d_{y}(\mathrm{~mm})$ & $d_{z}(\mathrm{~mm})$ & $d_{y}(\mathrm{~mm})$ & $d_{z}(\mathrm{~mm})$ \\
\hline 3-Weld-Seams & 0.378 & 2.108 & 0.473 & 2.188 & 0.302 & 2.054 \\
\hline 6-Weld-Seams & 0.901 & 4.739 & 1.087 & 4.648 & 0.899 & 4.425 \\
\hline
\end{tabular}


to confirm the accuracy of the simulation models. According to the results of this work, several conclusions can be summarized as follows:

1) The TEP-FEM simulated results and measured data are in good agreement and indicate that the developed TEP-FEM analysis can be used to accurately predict the welding distortion in a welded pipe structure.

2) In this proposed ISM, the obtained inherent strain is directly applied as an orthotropic artificial thermal expansion coefficient to the elastic FEM model, and the residual distortion produced by multi-seam welding of a pipe is derived from the unit thermal load step by step

3) The predicted welding distortion by the proposed ISM is in good coincidence with measured data and TEP-FEM simulation results. It is discovered that the proposed ISM has good performance in simulation accuracy and efficiency.

4) Compared with TEP-FEM simulation, the significant advantage of the proposed ISM is that computational efficiency can be increased by about 50 times.

ORCID: Chunbiao Wu: https://orcid.org/0000-0001-6365-443X ORCID: Jae-Woong Kim: https://orcid.org/0000-0003-0291-0844

\section{Reference}

1. G. Verhaeghe, Predictive formulae for weld distortion a critical review. United Kingdom, Woodhead Publishing Ltd (1999).

2. Y. Uada and T. Yamakawa. Analysis of thermal elastic-plastic stress and strain during welding by finite element method, Trans. JWRI, 2(2) (1971) 90-100.

3. D. Venkatkumar and D. Ravindran, 3D finite element simulation of temperature distribution, residual stress and distortion on 304 stainless steel plates using GTA welding, J. Mech. Sci. Technol. 30(1) (2016) 67-76. https://doi.org/10.1007/s12206-015-1208-5

4. R. N. Lidam, Y. H. P. Manurung, E. Harumanet, M. R. Redza, M. R. Rahim, M. S. Sulaiman, M. Y. Zakaria, G. Tham, S. K. Abas, and C. Y. Chau, Angular distortion analysis of the multipass welding process on combined joint types using thermo-elastic-plastic FEM with experimental validation, Int. J. Adv. Manuf. Technol. 69 (2013) 2373-2386.

https://doi.org/10.1007/s00170-013-5184-6

5. Y. H. P. Manurung, R. N. Lidam, M. R. Rahim, M. Y. Zakaria, M. R. Redza, M. S. Sulaiman, G. Tham, and S. $\mathrm{K}$. Abas, Welding distortion analysis of multipass joint combination with different sequences using 3D FEM and experiment, Int. J. Press. Vessel. Pip. 111-112 (2013) 89-98.

https://doi.org/10.1016/j.ijpvp.2013.05.002

6. S. K. Velaga, G. Rajput, S. Murugan, A. Ravisankar, and S. Venugopal, Comparison of weld characteristics between longitudinal seam and circumferential butt weld joints of cylindrical components, J. Manuf. Process. 18 (2015) 1-11.

https://doi.org/10.1016/j.jmapro.2014.11.002

7. Y. Ueda, K. Fukuda, and M. Tanigawa, New measuring method of three dimensional residual stresses based on theory of inherent strain (welding mechanics, strength \& design), Trans. JWRI, 8(2) (1979) 249-256.

8. Y. Luo, H. Murakawa, and Y. Ueda, Prediction of welding deformation and residual stress by elastic FEM based on inherent strain (first report): mechanism of inherent strain production, Trans. JWRI, 26(2) (1997) 49-57.

9. J. Wang, S. Rashed, and H. Murakawa, Mechanism investigation of welding induced buckling using inherent deformation method, Thin-Walled Struct. 80 (2014) 103-119.

https://doi.org/10.1016/j.tws.2014.03.003

10. N. Ma, J. Wang, and Y. Okumoto, Out-of-plane welding distortion prediction and mitigation in stiffened welded structures, Int. J. Adv. Manuf. Technol. 84 (2016) 1371-1389. https://doi.org/10.1007/s00170-015-7810-y

11. D. Deng, H. Murakawa, and W. Liang, Numerical simulation of welding distortion in large structures, Comput. Methods Appl. Mech. Eng. 196 (2007) 4613-4627. https://doi.org/10.1016/j.cma.2007.05.023

12. J. Wang, N. Ma, H. Murakawa, B. Teng, and S. Yuan, Prediction and measurement of welding distortion of a spherical structure assembled from multi thin plates, Material and Design, 32 (2011) 4728-4737. https://doi.org/10.1016/j.matdes.2011.06.047

13. J. Wang, H. Zhao, J. Zou, H. Zhou, Z. Wu, and S. Du, Welding distortion prediction with elastic FE analysis and mitigation practice in fabrication of cantilever beam component of Jack-up drilling rig, Ocean Eng. 130 (2017) 25-39. https://doi.org/10.1016/j.oceaneng.2016.11.059

14. Y. S Ha., S. H. Cho, and T. W. Jang, Development of welding distortion analysis method using residual strain as boundary condition, Materi. Sci. Forum, 580- 582 (2008) 649-654.

https://doi.org/10.4028/www.scientific.net/MSF.580-582.649

15. J. M. Lee, H. D. Seo, and H. Chung, Efficient welding distortion analysis method for large welded structures, J. Mater. Proc. Tech. 256 (2018) 36-50. https://doi.org/10.1016/j.jmatprotec.2018.01.043

16. M. Kim, M. Kang, and H. Chung, Simplified welding distortion analysis for fillet welding using composite shell elements, Int. J. Nav. Archit. Ocean Eng. 7 (2015) 452-465. https://doi.org/10.1515/ijnaoe-2015-0032

17. C. Wu, C. Lee, and J. W. Kim, Numerical simulation of bending deformation induced by multi-seam weld- 
ing of a steel-pipe structure, J. Mech. Sci. Technol. 34(5) (2020) 2121-2131.

https://doi.org/10.1007/s12206-020-0433-8

18. Y. Ueda, K. Fukuda, K. Nakacho, and S. Endo, A new measuring method of residual stresses with the aid of finite element method and reliability of estimated value, J. Soc. Nav. Arch. Japan, 138 (1975) 499-507. https://doi.org/10.2534/jjasnaoe1968.1975.138_499

19. J. Wang, H. Yuan, N. Ma, and H. Murakawa, Recent research on welding distortion prediction in thin plate fabrication by means of elastic FE computation, Marine Struct. 47 (2016) 42-59.

https://doi.org/10.1016/j.marstruc.2016.02.004
20. S. H. Cho and J. W. Kim, Analysis of residual stress in carbon steel weldment incorporating phase transformations, Sci. Technol. Weld. Join. 7(4) (2002) 212-216. https://doi.org/10.1179/136217102225004257

21. D. Deng, Y. Zhou, T. Bi, and X. Liu, Experimental and numerical investigations of welding distortion induced by $\mathrm{CO}_{2}$ gas arc welding in thin-plate bead-on joints, Mater. Des. 52 (2013) 720-729.

https://doi.org/10.1016/j.matdes.2013.06.013

22. J. Goldak, A. Chakravarti, and M. Bibby, A new finite element model for welding heat sources, Metall. Trans. B, 15 (1984) 299-305.

https://doi.org/10.1007/BF02667333 